\title{
GASTROENTEROPANCREATIC NEUROENDOCRINE TUMORS (GEP-NETs) - APPROACH TO DIAGNOSIS AND MANAGEMENT.
}

\author{
A.O. Oladejo
}

Correspondence:

\section{Dr. A.O. Oladejo}

Charite Campus Virchow-Klinikum,

Hepatology, Gastroenterology and Endocrine Unit, Augustenburger Platz 1, Berlin,

Germany.

\section{INTRODUCTION}

Neuroendocrine tumors comprise heterogeneous group of neoplasms which originate from endocrine cells, both within endocrine organs and within the cells of diffuse endocrine system. These tumors have variable clinical behavior ranging from well-differentiated, slow growing tumors to poorly-differentiated, highly invasive malignancies. These tumors generally fall into two broad categories;

(1) A group of neuroendocrine tumors that has the biology and natural history of a high grade malignancy and a characteristic small cell with undifferentiated or anaplastic appearance by light microscopy. WHO classifies this group of tumors as poorly differentiated neuroendocrine carcinomas. A typical example is the small cell lung cancer.

(2) The second group has variable but most often indolent biological behavior and characteristic well-differentiated histologic features. The majority of these tumors arise in the gastrointestinal tract and collectively, they are referred to as gastroenteropancreatic neuroendocrine tumors (GEP-NETs) ${ }^{1,2}$.

Gastroenteropancreatic neuroendocrine tumors can also be classified as functioning or non-functioning tumors. The term "non-functioning" refers to the absence of clinical syndromes of hormonal hypersecre- tion. The functioning tumors include insulinoma, glucagonoma, gastrinoma, VIPoma and somatostatinoma.

\section{Clinical Presentation and Natural History}

The clinical course of patients with GEP-NETs is highly variable. Some patients with indolent tumors remain symptom free for year even without treatment. Most patients with non-functioning tumors due to lack of symptoms related to hormonal hypersecretion are diagnosed late in the course of the disease. Clinical signs and symptoms are due to tumor mass with local invasion and distant metastases. These symptoms may include abdominal pain, weight loss, anorexia, nausea, jaundice, intra-abdominal mass and bleeding. Patients with functioning metastatic islet cell tumors typically manifest with symptoms caused by specific type of hormone produced by the tumor. With metastatic carcinoids, the secretion of serotonin and other vasoactive substances causes the carcinoid syndrome which manifests as episodic flushing, wheezing, diarrhea, pellagra-like skin lesions and eventual right-sided valvular heart disease. The carcinoid syndrome is most commonly seen with mid-gut carcinoid tumors (small intestine, appendix and proximal large bowel) and mostly in the setting of metastatic disease ${ }^{3,4,5,6}$.

\begin{tabular}{|l|l|l|}
\hline Tumor & Clinical Syndrome & Hormone \\
\hline Insulinoma & Hypoglycemia & Pro-insulin, Insulin \\
Gastrinoma (ZE Syndrome) & Peptic ulcer, diarrhea & Gastrin \\
VIPoma (VM Syndrome) & Watery diarrhea, hypokalemia & VIP \\
Glucagonoma & Anemia, diabetes, NME & Glucagon \\
Somatostatinoma & Diabetes, diarrhea, steatorrhea & Somatostatin \\
& Gallstones & GHFR \\
GHFRoma & Acromegaly & ACTH \\
ACTHoma & Cushing's syndrome & \\
\hline
\end{tabular}

ZE-Zollinger-Ellison, VM-Vemer-Morrison, VIP-Vasoactive intestinal peptide, GHFR- Growth hormone releasing factor, ACTH-Adenocorticotropic hormone, NME- Necrolytic migratory erythema. 


\section{Diagnosis}

Computed tomography and Ultrasonography.

With ultrasonography, most small lesions appear hypoechoeic while larger lesions are more heterogeneous, due to different degrees of hyalinised stroma, hemorrhage and cystic degeneration. Non-contrast enhanced CT imaging displays isodense or hypodense lesions compared to the adjacent pancreatic parenchyma while with contrast enhancement, the hypervascularity of endocrine tumor is apparent and characteristic $^{7,8,9}$.

\section{Magnetic Resonance Imaging (MRI)}

Newer techniques such as short term inversion recovery sequences have markedly improved the sensitivity of MRI for detecting primary NETs and liver metastasis and is thus a very useful investigative tool for tumor staging and planning appropriate therapy ${ }^{10}$.

\section{Endoscopic Ultrasound (EUS)}

Provides high resolution images of structures within or just beyond the wall of gastrointestinal tract, which allows the detection of lesions down to $0.3-0.5 \mathrm{~cm}$. EUS is also a useful tool in the diagnosis and staging of neuroendocrine tumors ${ }^{11,12}$.

\section{Somatostatin Receptor Scintigraphy (SRS)}

SRS has a sensitivity and specificity of $90 \%$ and $80 \%$ respectively for pancreatic neuroendocrine tumors. It has become an important diagnostic tool for localization of the primary lesion and definition of the extent of the disease. Whole body imaging allows for detection of distant metastases and thus influences therapeutic decisions. Over $90 \%$ of GEP-NETs contain high concentrations of somatostatin receptors which can be imaged using a radio-labelled form of somatostatin analog (Indium-111 pentetreotide, octreoscan). Single photon emission computed tomography (SPECT) using Gadolinium- DOTATOC to visualize somatostatin receptors is now an emerging tool in the evaluation of patients with GEP-NETs, especially metastatic liver disease $\mathrm{e}^{13,14,15,16,17,18}$.

\section{Biochemical Testing}

Chromogranin A is a general tumor marker for neuroendocrine tumors. Urinary 5-hydroxyl indolacetic acid (5-HIAA) is useful in the diagnosis and monitoring response to therapy in patients with metastatic carcinoid tumors. Other tumor markers which may be useful though not as clinically important as chromogranin A are serotonin, neuropeptide K, Substance $\mathrm{P}$, alpha-feto protein, human chorionic gonadotropin, neurone-specific enolase, calcitonin gene related peptide, neuro D, neurogenin 3, pancreastatin, CDX-2 and SERPIN $10 \mathrm{~A}^{19}$.

\section{Pathology}

Neuroendocrine tumors have variable biologic activities with histology being the gold standard in establishing a definitive diagnosis. Immunohistochemical detection of Chromogranin A and synaptophysin is necessary in ascertaining the neuroendocrine nature and origin of the suspected tumor. Evaluation of the mitotic count or Ki-67 index is essential in determining the biologic nature, prognosis of the tumor and choosing the optimal therapeutic approach ${ }^{20}$.

\section{Medical Management}

Somatostatin Analogs (SSA)

The mechanisms by which somatostatin and its analogs exert their effect on the NET cells are complex. Somatostatin is known to inhibit different cellular function, such as secretion, motility and proliferation.SSAs have been used in the treatment of NETs and specifically GEP-NETs for many years and are highly effective in controlling symptoms associated with carcinoid tumors, VIPomas and glucagonomas. The efficacy of SSA is somewhat predictable for symptomatic patients with insulinoma and gastrinoma. Notable examples of SSAs include octreotide which is a short acting SSA which requires frequent dosing and lanreotide which is a long acting formulation that may be given on a monthly basis. Pasireotide (SOM230) is a novel, multi-ligand somatostatin that exhibits high binding affinity to somatostatin receptor subtypes 1 , 2, 3 and 5. SSAs are usually well tolerated but minor side effects include abdominal discomfort, bloating, steatorrhea and gallstones which are usually asymptomatic $21,22,23,24,25$.

\section{Interferons}

Interferon is given for the same indications as SSAs but untoward side-effects such as depression, disabling fatigue, myelosuppression and alteration in thyroid functions have limited their use to being a second line therapy in the management of GEP-NETs. Combined therapy with interferon and somatostatin analogs can control symptoms in patients with the carcinoid syndrome who are resistant to somatostatin analogs alone $26,27,28$.

\section{Chemotherapy}

Single agent therapy with 5-fluorouracil (5-FU), streptozocin, doxorubicin, etoposide, or dacarbazine is associated with modest response rates in metastatic carcinoid tumors. A combination of streptozocin with 5-FU or doxorubicin has been used for some decades with varying objective tumor responses. Other chemotherapeutic agents that could also be used include temozolomide, dacarbazine, cisplastin, etoposide and capecitabine c9,30,31,32. $^{2}$. 


\section{Molecular-Targeted Therapy}

Gastrointestinal Neuroendocrine tumors over-express several growth factors, including vascular endothelial growth factor (VEGF), basic fibroblast growth factors (b-FGF), platelet - derived growth factor (PDGF) and insulin like growth factor (IGF-1). Neuroendocrine tumors have long been known to be highly vascular and inhibition of VEGF receptor has the potential for tumor growth inhibition and in some cases tumor regression. Bevacizumab is a monoclonal antibody targeting VEGF which may be useful in the future management of pancreatic NET. Sunitinib, sorafenib, imatinib and gefitinib are small tyrosine kinase inhibitors have also been evaluated in various clinical trials with varying response rates. The mammalian target of rapamycin (mTOR) is a threonine kinase that mediates downstream signaling in a number of pathways that are implicated in the growth of neuroendocrine tumor. Activation of the PI3K/AKT/ m TOR pathway has been shown to cause increased translation of proteins regulating cell cycle progression and inhibitors of mTOR ( everolismus and temsirolimus) have recently shown promising activity in a number of cancer types ${ }^{33,34,35,36}$.

\section{Surgical Therapy and Ablative Therapy}

The type of surgery depends on the localization, size, extent, suspected malignancy and the presence of metastasis. Localized malignant tumors larger than $2 \mathrm{~cm}$ may require aggressive surgery and sometimes resection of nearly nearby organs or major vessel resection. Hepatic resection is indicated for the treatment of liver metastasis in the absence of diffuse bilobar involvement, compromised liver function, or extensive extrahepatic metastases and may provide longterm symptomatic relief and also prolong survival. Other modalities of therapy especially in extensive liver metastases include trans-catheter arterial embolization (TAE), trans- catheter arterial chemoembolization (TACE), radiofrequency ablation (RFA), radioembolization, laser-induced thermotherapy (LITT), percutaneous ethanol injection and brachytherapy, generally referred to as ablative therapies. Radiofrequency ablation is usually employed in extensive liver metastases less than $3 \mathrm{~cm}$ while TAE or TACE are employed in the treatment of larger tumor masses. Liver transplantation may be the last resort in some carefully chosen patients but the exclusion of extra-hepatic metastases must be guaranteed prior to transplantation ${ }^{37,38,39,40,41,42}$.

\section{Radionuclide Therapy}

Peptide receptor radionuclide therapy (PPRT) with somatostatin analogs coupled with beta- emitting radionuclides is currently a useful therapeutic option in patients with inoperable neuroendocrine tumors with sufficient uptake on diagnostic SRS. The two most commonly used radionuclides in neuroendocrine tumors are Yttrium $\left({ }^{90} \mathrm{Y}\right)$ and Lutetium $\left({ }^{177} \mathrm{Lu}\right)$. Yttrium is a pure beta emitter and the range of the emitted particle is greater than the diameter of the cell and may result in crossfire involving neighboring cells while Lutetium emits a shorter range, lower energy beta particle suitable for smaller tumors and in addition emits a gamma radiation, facilitating imaging after therapy $y^{43,44,45,46}$.

\section{CONCLUSION}

Gastroentreopancreatic neuroendocrine tumors represent a wide range of benign to highly malignant tumors originating from the endocrine cells with a highly variable clinical course. The approach to the management of this complex group of tumors usually involves a multi-disciplinary group of experts- endocrinologists, radiologists, pathologists, interventional radiologists, clinical oncologists, nuclear medicine specialists and surgeons. The management may occasionally be highly challenging and intriguing to both the patient and the medical expert due to the complex nature of the disease and the overwhelming cost of highly sophisticated procedures and therapy. Finally, neuroendocrine tumor represents a group of seemingly rare diseases but with an ever expanding scope of both basic and clinical research.

\section{REFERENCES}

1. Rufini V., Calcagni M.L., Baum R.P.: Imaging of Neuroendocrine tumors. Semin Nucl. Med. 2006; 36:228-247.

2. Kloppel G., Perren A., Heitz P.U. The gastroenteropancreatic neuroendocrine cell system and its tumor: the WHO classification. Ann N Y Acad Sci 2004; 1014:13.

3. Cheslyn-Curtis S., Sitaram V., Williamson R.C. Management of non-functioning Neuroendocrine tumors of the pancreas. Br. J. Surg 1993; 80: 625627.

4. Madura J.A., Cummings O.W., Wiebke E.A. et al. Non-functioning islet cell tumors of the pancreas: a difficult diagnosis but one worth the effort. Am Surg 1997; 63:573-577.

5. White T.J., Edney J.A., Thompson J.S., et al. Is there a prognostic difference between functional and non-functional islet cell tumors? Am J Surg 1994; 168:627-629.

6. Thorson A., Biorck G., Bjorkman G., Waldenstrom J. Malignant carcinoid of the small 
intestine with metastases to the liver, valvular disease of the right side of the heart (pulmonary stenosis and tricuspid regurgitation without septal defects), peripheral vasomotor symptoms, bronchoconstriction, and an unusual type of cyanosis: a clinical and pathologic syndrome. Am Heart J 1954: 47:795.

7. Beutow P.C., Miller D.L., Parrino T.V., Buck J.L.: Islet cell tumors of the pancreas: clinical, radiologic, and pathologic correlation in diagnosis and localization. Radiographics 1997; 17: 453-472.

8. Fidler J.L., Johnson C.D. Imaging of Neuroendocrine tumors of the pancreas. Int. J Gastrointest Cancer 2001; 30:73-85.

9. Kalra M.K., Maher M.M., Mueller P.R., Saini S. State- of -the art imaging of pancreatic neoplasms. Br J Radiol 2003; 76: 857-865.

10. Semelka R.C., Custodio C.M., Cem Balci N., Woosley J.T. Neuroendocrine tumor of the pancreas: spectrum of appearances on MRI. J Magn Reson Imaging 2000; 11:141-148.

11. Vilmann P., Hancke S., Henriksen F.W., Jacobsen G.K. Endosonographically guided fine needle aspiration biopsy of malignant lesions in the upper gastrointestinal tract. Endoscopy 1993; 25:523-527.

12. Anderson M.A., Carpenter S., Thompson N.W., Nostrant T.T., Elta G.H., Scheimann J.M. Endoscopic ultrasound is highly accurate and directs management in patients with Neuroendocrine tumors of the pancreas. Am J Gastroenterol 2000; 95:2271-2277.

13. Lebtahi R., Cadiot G., Sarda L., et al. Clinical impact of somatostatin receptor scintigraphy in the management of patients with Neuroendocrine gastroenteropancreatic tumors. J Nucl Med 1997; 38:853-858.

14. Krenning E.P., Kwekkeboom D.J., Bakker W.H., et al. Somatostatin receptor scintigraphy with $\left({ }^{111} \mathrm{In}\right.$ DTPA-D-Phe1)- and ( $\left.{ }^{123} \mathrm{I}-\mathrm{Tyr} 3\right)$ - octreotide: the Rotterdam experience with more than $1000 \mathrm{pa}-$ tients. Eur J Nucl Med 1993; 20:716-731.

15. Ricke J., Klose K.J. Imaging procedures in Neuroendocrine tumors. Digestion 2000; 62(suppl 1):39-44.
16. Lambert S., Bakker W., Reubi J., Krenning E. Somatostatin receptor imaging in the localization of endocrine tumors. N Engl J Med 1990; 323:1246.

17. Kvols L.K., Brown M.L., O’Connor M.K., et al. Evaluation of a radio-labeled somatostatin ana$\log$ ( I-123 octreotide) in the detection and localization of carcinoid and islet cell tumors. Radiology 1993; 187:129.

18. Kaltsas G., Korbonits M., Heintz E., et al. Comparison of somatostatin analog and metaiodobenzyl guanidine radionuclites in the diagnosis and localization of advanced neuroendocrine tumors. J Clin Endocrinol Metab 2001; 86:895.

19. Eriksson B., Oberg K., Stridsberg M. Tumor markers in neuroendocrine tumors. Digestion 2000; 62 Suppl 1:33-38.

20. Vilar E., Salazar R., Garcia J.P., Cortes J., Oberg K., Tabernero J. Chemotherapy and role of the proliferation marker $\mathrm{Ki}$ - 67 in digestive Neuroendocrine tumors. Endocrine-Related Cancer 2007; 14:221-232.

21. Ricci S., Antonuzzo A., Galli L., et al. Long-acting depot lanreotide in the treatment of patients with advanced neuroendocrine tumors. Am J Clin Oncol 2000; 79:180.

22. Kraenzlin M., Ch'ng J., Wood S., et al. Long-term treatment of a VIPoma with somatostatin analog resulting in remission of symptoms and possible shrinkage of metastases. Gastroenterology 1985; $88: 185$.

23. Aparicio T., Ducreux M., Baudin E., et al. Antitumor activity of somatostatin analogs in progressive metastatic Neuroendocrine tumors. Eur J Cancer 2001; 37:1014.

24. Arnold R., Trautmann M.E., Creutzfeldt W., et al. Somatostatin analog octreotide and inhibition of tumor growth in metastatic endocrine gastroenteropancreatic tumors. Gut 1996; 38: 430438.

25. Ben-Shlomo A., Melmed S. Pasireotide- a somatostatin analog for potential treatment of acromegaly, Neuroendocrine tumors and Cushing's disease. Drug 2007 Dec; 10(12):885-895.

26. Bajetta, et al. Treatment of metastatic carcinoid and other Neuroendocrine tumors with recom- 
binant interferon-alpha-2a. A study by the Italian Trials in Medical Oncology Group. Cancer 1993; 72:3099.

27. Janson E., Oberg K. Long-term management of the carcinoid syndrome: treatment with octreotide alone and in combination with alphainterferon. Acta Oncol 1993; 32:225.

28. Frank M., Klose K.J., Wied M., et al. Combination therapy with octreotide and alpha-interferon: effect on tumor growth in metastatic endocrine gastroenteropancreatic tumors. Am J Gastroenterol 1999; 94:1381.

29. Kulke M.H., Mayer R.J. Carcinoid tumors. N Engl J Med 1999; 340:858.

30. Moertel C.G., Lefkopoulo M., Lipsitz, et al. Streptozocin-doxorubucin, streptozocine-fluorouracil or chlorozotocin in the treatment of advanced islet -cell carcinoma. N Engl J Med 1992; 326:519523.

31. Fjallskog M.L., Granberg D.P., Welin S.L., et al. Treatment with cisplatin and etoposide in patients with Neuroendocrine tumors. Cancer 2001; 92:1101-1107.

32. Pavel M.E., Baum U., Hahn E.G., Hensen J. Doxorubucin and streptozocin after failed biotherapy of Neuroendocrine tumors. Int J Gastrointest Cancer 2005; 35 179-185.

33. Yao J.C., Phan A., Hoff P.M., et al. Targeting vascular endothelial growth factor in advanced carcinoid tumors: a random assignment phase II study of depot octreotide with bevacizumab and pergylated interfereon alpha-2b. J Clin Oncol 2008; 26: 1316.

34. Kulke M.H., Lenz H.J., Meropol N.J., et al. Activity of sunitinib in patients with advanced neuroendocrine tumors. J Clin Oncol 2008; 26:3403.

35. Smolewski. Recent developments in targeting the mammalian target of rapamycin (mTOR) kinase pathway. Anticancer Drugs 2006; 17: 487.

36. Yao S.C., Phan A.T., Chang D.Z., et al. Efficacy of RAD 001 (everolimus) and octreotide LAR in advanced low- to intermediate grade neuroendocrine tumors. Br J Cancer 2006; 95:1148.

37. Sarmiento J.M., Heywood G., Rubin, et al. Surgical treatment of neuroendocrine metastases to the liver: a plea for resection to increase survival. J Am Coll Surg 2003; 197:29.

38. Landry C.S., Scoggins C.R., McMasters K.M., Martin R.C. Management of hepatic metastases of gastrointestinal carcinoid tumors. J Surg Oncol 2008; 97:253.

39. Siperstein A., Berber E. Cryoablation, percutaneous alcohol injection, and radiofrequency ablation for treatment of Neuroendocrine liver metastases. World J Surg 2001; 25: 693-696.

40. Atwell T.D., Charboneau J.W., Que F.G., Rubin J., Lewis B.D., Nagorney D.M., Callstrom M.R., Farrell M.A., Pitot H.C., Hobday T.J. Treatment of Neuroendocrine cancer metastatic to the liver: role of ablative techniques. Cardiovasc Intervent Radiol 2005; 28: 409-421.

41. Mitty H.A., Warner R.R., Newman L.H., Train J.S., Parnes I.H. Control of carcinoid syndrome with hepatic artery embolization. Radiology 1985; 155: 623-626.

42. Roche A., Girish B.V., de Baere T., Baudin E., Bioge V., Elias D., Lasser P., Schlumberger M., Ducreux M. Trans-catheter arterial chemoembolization as first-line treatment for hepatic metastases from endocrine tumors. Eur Radiol 2003; 13:136-140.

43. Kwekkeboom D.J., Bakker W.H., Kam B.L, et al. Treatment of patients with gastroenteropancreatic tumors with the novel radio-labeled somatostatin analog $\left[{ }^{177} \mathrm{Lu}-\mathrm{DOTA}(0)\right.$, Tyr3] octreotate. Eur J Nucl Med Mol Imaging 2003; 30:417-422.

44. Kwekkeboom, D.J., Mueller-Brand J., Paganelli G., et al. Overview of results of peptide receptor radionuclide therapy with 3 radio-labeled somatostatin analogs. J Nucl Med 2005; 46(suppl 1):6266.

45. Krenning E.P., de Jong M., Kooij P.P., Breeman W.A., Bakker W.H., de Herder W.W., van Eijck C.H., Kwekkeboom D.J., Jamar F., Pauwels S., Valkema R. Radio-labeled somatostatin analog for peptide receptor scintigraphy and radionuclide therapy. Ann Oncol 1999; 10(suppl 2):23-29.

46. de Jong M., Kwekkeboom D., Valkema R., Kreening E.P. Radio-labeled peptides for tumor therapy: current status and future directions. Plenary lecture at the EANM 2002. Eur J Nucl Med Mol Imaging 2003; 30:463-469. 